\title{
Adverse Role of Aggressive Fluid Therapy in Severe Acute Pancreatitis
}

\author{
Jorge Enrique Martínez López ${ }^{1}$, Juan Carlos Rivera Acosta ${ }^{2 *}$, William Andrés Jaramillo Cabrera ${ }^{3}$, José \\ Antonio Reyes Pinto ${ }^{1}$, Manuel Francisco Mejía Rincón ${ }^{1}$, José Luis Olivera Ochoa ${ }^{1}$, Manuel Segundo \\ Castaño Ochoa ${ }^{1}$, Mario Alberto Gutiérrez Villarreal ${ }^{4}$, Ricardo Javier Galván Zúñiga ${ }^{5}$, Faruk Hernandez \\ Sampayo $^{6}$, Jakelin Dayanna Mercado Soto ${ }^{7}$ and Adams Mattos Amaris ${ }^{7}$
}

${ }^{1}$ General Physician, Universidad del Sinú, Montería, Colombia

${ }^{2}$ General Physician, Universidad Cooperativa de Colombia

${ }^{3}$ General Physician, Universidad Libre Seccional, Cali-Colombia

${ }^{4}$ General Physician, Universidad del Norte, Barranquilla, Colombia

${ }^{5}$ Intern Physician, Universidad del Sinú, Montería, Colombia

${ }^{6}$ General Surgeon, Universidad Metropolitana, Barranquilla, Colombia

${ }^{7}$ General Physician, Corporación Universitaria Rafael Nuñez, Cartagena, Colombia

\begin{abstract}
Acute pancreatitis (AP) is a disease that currently lacks specific treatment. Measures such as early endoscopic sphincterotomy or prophylactic antibiotic therapy in severe AP have not shown a clear benefit in published meta-analyzes. For this reason, in clinical practice guidelines and systematic reviews, supportive treatment is highlighted as the most important measure to improve the clinical course of this disease, and in particular, early and aggressive fluid therapy is recommended. It is important to perform this review to gather the most recent information available about severe acute pancreatitis, emphasizing diagnosis and treatment in order to offer the majority of patient's adequate management. Being such a common pathology in the emergency service and taking into account the high morbidity-mortality that it can present.
\end{abstract}

KEYWORDS: Fluid therapy; Acute pancreatitis

\section{INTRODUCTION}

The pancreas is an abdominal organ with a large number of functions such as secreting various digestive enzymes and vital hormones. Anatomically, its cells are divided into two portions (endocrine - exocrine) that are related to their functions, the endocrine pancreas is responsible for producing digestive enzymes, including lipases, proteinases and amylases, responsible for the metabolism of fats, proteins and carbohydrates for their absorption and It comprises less than $5 \%$ of the total mass of the pancreas, contains different types of cells, which are responsible for secreting a different hormone each: $\alpha$ cells (glucagon), $\beta$ cells (insulin), $\delta$ cells (somatostatin), cells $\mathrm{P}$ (polypancreatic peptide), and $\varepsilon$ cells (ghrelin).

The exocrine pancreas contains acini, which secrete pancreatic juice into the duodenum through the pancreatic ducts, it contains several enzymes, some of which are initially synthesized in an inactive form. Once activated, these enzymes help digest food and prepare it for absorption in the intestine. Disorders that interfere with the normal activity of pancreatic enzymes (pancreatic insufficiency) result in poor digestion of fat and steatorrhea (fatty stools). Acute pancreatitis is a sudden inflammatory process
Quick Response Code:

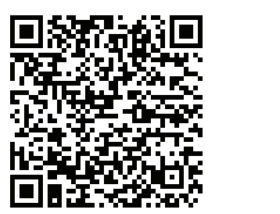

Address for correspondence: Juan Carlos Rivera Acosta, General Physician, Universidad Cooperativa de Colombia

Received: September 01, $2021 \quad$ Published: September 20, 2021

How to cite this article: Jorge EML, Juan CRA, William AJC, José ARP, Manuel FMR, etc. Adverse Role of Aggressive Fluid Therapy in Severe Acute Pancreatitis. 2021- 3(5) OAJBS.ID.000319. DOI: 10.38125/OAJBS.000319 
of the pancreas, in $80 \%$ of cases it is predominantly local and mild, without relevant systemic consequences and without local complications, and it is one of the gastrointestinal disorders that most commonly requires evaluation in the emergency service. It is associated with systemic and metabolic disturbances due to the release of hydrolytic enzymes, toxins, and cytokines and can result in the failure of various organs and systems.

Severe acute pancreatitis is a disease with a highly variable presentation and causes significant morbidity and mortality in severe cases. It is characterized by a variable spectrum of the disease, ranging from mild ( $80 \%$ of cases), where the patient recovers in a few days, to severe (20\% of cases), with prolonged hospital stays, the need for intervention in critical care and up to $15-20 \%$ mortality. In most patients, only edema of the pancreas occurs. However, in $20 \%$ the course of pancreatitis is unfavorable, associated with high morbidity and considerable mortality. There are 2 components that can overshadow the evolution of AP: local complications (acute collections, necrosis of the pancreatic gland and peripancreatic fat) and systemic complications (systemic inflammatory response syndrome [SIRS] and organ failure). Due to its variable costs, we speak of timely treatments according to the clinical characteristics of each patient, however, globally, there is no established and clear management for the treatment of acute pancreatitis.

\section{MATERIALS AND METHODS}

A detailed bibliographic search of information published since 2015 is carried out, in the databases pubmed, Elsevier, scielo, Update, medline, national and international libraries. We use the following descriptors: Fluid therapy, acute pancreatitis. The data obtained oscillate between 5 and 15 records after the use of the different keywords. The search for articles was carried out in Spanish and English, it was limited by year of publication and studies published since 2015 were used.

\section{RESULTS}

There is a debate in recent years about whether early aggressive fluid therapy is helpful or harmful in severe sepsis. The objective was to expand the effective blood volume to attenuate hypotension, improve peripheral and organ perfusion, and correct alterations in base and lactate deficits [1]. Volume expansion has not been shown to be beneficial in increasing cardiac output. There is also no data to confirm that aggressive fluid therapy improves blood pressure or target organ perfusion [2] In the past decade the famous article by Riverset al., Published in The New England Journal of Medicine, has dominated the sepsis landscape. "Early goal-directed therapy in the treatment of severe sepsis and septic shock". The study randomized patients with severe sepsis or septic shock to receive $6 \mathrm{~h}$ of standard treatment (objectives: central venous pressure $\geq 8$ $12 \mathrm{mmHg}$, mean arterial pressure $\geq 65 \mathrm{mmHg}$, diuresis $\geq 0.5 \mathrm{ml} / \mathrm{kg}$ /h) versus early treatment based on specific objectives (those of standard treatment and a central venous oxygen saturation $\geq 70 \%$ ). The fluids were managed as follows: bolus of $500 \mathrm{ml}$ of crystalloids every $30 \mathrm{~min}$ until a central venous pressure (CVP) of 8 to $12 \mathrm{mmHg}$ was obtained. In the case of having a mean arterial pressure lower than $65 \mathrm{mmHg}$, vasopressors were administered to at least reach that figure. Vasodilators were administered if the mean arterial pressure was $\geq 90 \mathrm{mmHg}$, until it fell below that figure. 263 patients were included. The group based on early goal-based treatment had a mortality of $30.5 \%$ versus $46.5 \%(p<0.01)$ [3].
The relationship between aggressiveness of fluid administration and prognosis is controversial. In a retrospective study, 39 patients with a hematocrit $\geq 44 \%$ on admission were selected $[4,5]$. No significant differences were found in the amount of fluids among those who developed acute severe interstitial and necrotizing pancreatitus, which indicates that the volume of fluids was not a determining factor for the development of pancreatic necrosis. A retrospective analysis in 99 patients showed that those who received more than $4 \mathrm{~L}$ in the first $24 \mathrm{~h}$ had more respiratory complications than those who received less fluids. This could be due to the direct effect of the fluids but also to the fact that patients with severe AP (which is associated with respiratory failure) sequester more fluids.

In another retrospective study, fluid therapy administered to 340 patients was analyzed. Patients who received less than a third of fluid therapy in the first 72 hours during the first day of admission had a worse prognosis (higher incidence of SIRS, organ failure, and hospital and ICU stay). The authors reason that these are patients who receive little relative fluid therapy during the first day of admission. The total volume of fluids administered in the first days of evolution was not related to the prognosis [6]. Very recently, an excellent systematic review with meta-analysis of the most relevant studies on fluid therapy in PA10 has been published. It included 4 randomized and controlled studies, where it was concluded (with a moderate quality of evidence) that a non-aggressive administration of fluids was associated with lower organ failure and mortality. The authors highlight the paucity and unequal quality of studies on fluid therapy in severe acute pancreatitis [7].

\section{DISCUSSION}

Intensive fluid therapy is often suggested in the treatment of severe acute pancreatitis. However, there is some controversy about the effect of this option on the appearance of clinical complications and the need for surgery. The correct hydration of patients with acute pancreatitis is a fundamental aspect in the treatment of this pathology, the main problem faced in the treatment of PAS taking into account that there is no standard nomenclature for intravenous hydration, also called by some authors as fluid replacement, resuscitation or resuscitation, similar to the term aggressive intravenous hydration or vigorous intravenous hydration. Another term used in the medical literature is fluid, fluid therapy [8]. There is great uncertainty about the efficacy and safety of currently recommended fluid administration regimens. Both an excessive supply of solutions and a deficient one are known to increase the risk of complications [9].

Supportive management through aggressive fluid hydration, analgesic monitoring continues to be the cornerstone of treatment for severe acute pancreatitis [10]. Early hydration is essential in the approach to maintain an effective circulating volume and a sufficient perfusion pressure that does not compromise pancreatic microcirculation. An ideal fluid scheme should take into account the weight, height and age of the patients, as well as the severity of the disease. However, a universal scheme has not been established that takes all variables into account or is considered totally safe [11]. One of the complications of aggressive hydration in patients with severe acute pancreatitis is fluid retention [12]. However, no significant relationship was observed between fluid therapy at 48 hours and death, or with the appearance of systemic complications. This, of course, raises the question of the "critical" value of fluids associated with each of a forementioned complications [13]. Early aggressive intravenous hydration is most beneficial during the first 6-12 hours, and may have little benefit after 24 hours, being 
a strong recommendation, with moderate quality of evidence [14]. However, there are studies that suggest that if more than 4 liters of fluid is given in the first 24 hours, it can make the disease worse, especially by causing pulmonary complications. There are studies where early aggressive intravenous hydration with lactate Ringer's solution accelerated clinical improvement in patients with mild acute pancreatitis [15]. In relation to the characteristics of the patients, it happens that those who have kidney problems or heart disease cannot receive much fluid, that is, they must be treated with standard resuscitation, which is less deleterious for them [16].

It is also argued that intravenous hydration is more effective if it is given with Ringer's lactate, however, the controversies found among the previously reviewed studies are fundamentally based on the fact that there is no clinical guideline to determine the adequate volume or adequate composition, the frequency or rate of administration, in this there is no consensus, and in part it is because the type of patient is subject to various conditions, for example obese or hypertensive patients, or who have other complications in their organs, causing the fluid volume is highly variable or even not recommended, hence the importance of having a protocol for both the doctor and the nurse [17]. Another factor that influences the intravenous administration of fluids, whether aggressive or standard, is that the treatment of patients with acute pancreatitis depends a lot on the degree of severity at the time they arrive at the emergency services, for this reason have detailed the instruments that were applied in the reviewed studies, of the scoring type or scores, such as APACHE, Ranson, Glasgow, BISAP and HAPS. In general, there are more studies where the use of aggressive intravenous hydration is recommended than the standard one, but in turn aggressive intravenous hydration is the one that has the most points against it because it can be harmful if it is applied late, and is sometimes associated with an increase in morbidity and mortality, for example in obese or overweight patients, great care should be taken due to possible respiratory problems that aggressive intravenous hydration could cause.

\section{CONCLUSION}

Since severe acute pancreatitis is an inflammatory type pathology that constitutes a very frequent public health problem in emergency services, and in whose therapeutic management much attention is paid to intravenous hydration as a therapeutic option, it is of vital importance to analyze and carry out case studies, research work where the importance of intravenous hydration, whether aggressive or standard, in patients with acute pancreatitis, in order to establish therapeutic doses that can be used in the majority of patients who meet the clinical condition to apply this treatment option. So far, and taking into account the articles reviewed, it can only be stated that the rate of disadvantage in the solution and approach of severe acute pancreatitis is greater.

\section{REFERENCES}

1. Mederos MA, Reber HA, Girgis MD (2021) Acute pancreatitis: a review. JAMA 325(4): 382-390.

2. Jardin F, Fourme T, Page B, Loubieres Y, Vieillard-Baron A, et al. (1999) Persistent preload defect in severe sepsis despite fluid loading: A longitudinal echocardiographic study in patients with septic shock. Chest 116(5): 1354-1359.

3. Rivers E, Nguyen B, Havstad S, Ressler J, Muzzin A, et al. (2001) Early goal-directed therapy in the treatment of severe sepsis and septic shock. N Engl J Med 345: 1368-1377.

4. Eckerwall G, Olin H, Andersson B, Andersson R (2006) Fluid resuscitation and nutritional support during severe acute pancreatitis in the past: what have we learned and how can we do better? Clin Nutr 25(3): 497504 .

5. Warndorf MG, Kurtzman JT, Bartel MJ, Cox M, Mackenzie T, et al. (2011) Early fluid resuscitation reduces morbidity among patients with acute pancreatitis. Clin Gastroenterol Hepatol 9(8): 705-709.

6. Gardner TB, Vege SS, Chari ST, Petersen BT, Topazian MD, et al. (2009) Faster rate of initial fluid resuscitation in severe acute pancreatitis diminishes in-hospital mortality. Pancreatology 9(6): 770-776.

7. Haydock MD, Mittal A, Wilms HR, Phillips A, Petrov MS, et al. (2013) Fluid therapy in acute pancreatitis: anybody's guess. Ann Surg 257(2): 182-188.

8. Trikudanathan G, Navaneethan U, Vege SS (2021) Current controversies in fluid resuscitation in acute pancreatitis: a systematic review. Pancreas 41(6): 827-834.

9. Wu BU, Comwell DL (2010) Update in acute pancreatitis. Curr Gastroenerol Rep 12(2): 82-90.

10. Wu BU, Johannes RS, Sun X, Conwell DL, Banks PA (2009) Early changes in blood urea nitrogen predict mortality in acute pancreatitis. Gastroenterology 137(1): 129-135.

11. Wu BU, Bakker OJ, Papachristou GI, Besselink MG, Repas K, et al. (2011) Blood urea nitrogen in the early assessment of acute pancreatitis: an international validation study. Arch Intern Med 171 (7): 669-676.

12. Janisch NH, Gardner TB (2016) Advances in management of acute pancreatitis. Gastroenterol Clin North Am 45(1): 1-8.

13. Tenner S, Baillie J, Dewitt J, Swaroop S (2013) American college of gastroenterology guideline: Management of acute pancreatitis. Am J Gastroenteroly 108(9): 1400-1415.

14. Lipovestky F, Tonell C, Ramos A, Cueto G, Guimaraens P, et al. (2016) Pancreatitis aguda: Su manejo en Cuidados Intensivos. Med Intensiva 33(1): 120-131.

15. Buxbaum J, Quezada M, Da B, Jani N, Lane Ch, et al. (2017) La hidratación agresiva temprana acelera el mejoramiento clínico en la pancreatitis aguda leve. The American Journal of Gastroenterology 112(1): 797-803

16. Mueller S, Reynolds P, MacLauren R (2017) Acute Pancreatitis, a sod story. McGraw-Hill Education, USA.

17. De-Madaria E, Garg P (2014) Fluid therapy in acute pancreatitis aggressive or adequate? Time for reappraisal. Pancreatology 14(6): 433435. 